\title{
WILHELM OSTWALD PARA ALÉM DO ANTIATOMISMO
}

\author{
Letícia dos Santos Pereiraa,*,®, Olival Freire Jr. , Artur José Santos Mascarenhas ${ }^{\mathrm{a}}$ e Gisela Boeck ${ }^{\mathrm{c}}$ \\ anstituto de Química, Universidade Federal da Bahia, 40170-115 Salvador - BA, Brasil \\ 'Instituto de Física, Universidade Federal da Bahia, 40170-115 Salvador - BA, Brasil \\ ${ }^{\mathrm{c}}$ Chemistry Institute, University of Rostock, 18059 Rostock, Germany
}

Recebido em 02/08/2020; aceito em 26/08/2020; publicado na web em 30/09/2020

\begin{abstract}
WILHELM OSTWALD BEYOND ANTIATOMISM. The Baltic German chemist Wilhelm Ostwald (1853-1932) had his scientific prestige eclipsed in the history of chemistry due to his rejection to atomic theory, which suggests the permanence of the whig interpretation on history of chemistry in the narratives about him. In this paper, we intend to present elements on Ostwald's biography far from his role in the atomic controversy from the $19^{\text {th }}$ century, as for example his efforts for the popularization of physical chemistry; his role as a teacher and a textbook writer, and his role as a chemical researcher, being responsible for relevant studies on chemical affinity and catalysis, for example. Finally, we conclude this paper defending that Ostwald's trajectory cannot be neglected for those interested in history of science.
\end{abstract}

Keywords: Wilhelm Ostwald; history of chemistry; catalysis; textbooks.

\section{INTRODUÇÃO}

A ideia de que os cientistas que se opuseram às novidades científicas de sua época eram sujeitos retrógrados ou incapazes de perceber o potencial das teorias e descobertas que surgiam, é uma representação criticada e há muito tempo abandonada pelos historiadores da ciência. Contudo, ainda é possível encontrar vestígios dessa abordagem que reduz alguns dos envolvidos em uma controvérsia ao papel de antagonista, ou os representa como obstáculos ao desenvolvimento científico. Este é o caso do químico báltico-alemão Wilhelm Ostwald (1853-1932).

Professor do Instituto Politécnico de Riga (1881-1887) e da Universidade de Leipzig (1887-1906), Ostwald foi um pesquisador inquieto e criativo. Seu interesse inicial em determinar quantitativamente as afinidades químicas, o levou a conhecer os químicos Svante Arrhenius (1859-1927) e Jacobus Henricus van't Hoff (1852-1911). Da interação entre eles, surgiram trabalhos importantes, como a Teoria de Dissociação Eletrolítica, proposta por Arrhenius em 1887, e a Lei de Diluição dos Ácidos, proposta por Ostwald em 1888. ${ }^{1}$ Enquanto professor da Universidade de Leipzig, Ostwald orientou dezenas de estudantes vindos de toda a Europa e de países como Japão e Estados Unidos. Seus interesses iam desde problemas físico-químicos, como o comportamento eletroquímico de soluções, equilíbrio químico e catálise, até assuntos mais gerais, como história da química, filosofia natural, teoria das cores, pacifismo, dentre outros. Em reconhecimento aos seus trabalhos sobre catálise, equilíbrio químico e velocidade de reações, Ostwald recebeu o Prêmio Nobel de Química em 1909.²

A despeito de tais contribuições, Ostwald é um personagem histórico pouco conhecido, quando não mal compreendido. Os compêndios de História da Química em língua portuguesa citam suas contribuições apenas superficialmente, ${ }^{3-5}$ enquanto alguns artigos de Ensino do Química destacam apenas seu papel na criação do conceito de $\mathrm{Mol}^{6,7}$ e sua contribuição para o desenvolvimento das ideias de ácido e base oriundas do trabalho de Arrhenius. ${ }^{8}$ Todavia, um elemento da trajetória de Ostwald é muito popular na literatura: sua rejeição pública à teoria atômica e posterior conversão ao atomismo.

*e-mail: leticiapereira@ufba.br
Formado dentro de uma tradição mecanicista da química e inicialmente simpático à hipótese atômica, Ostwald se afastou gradualmente destas em favor de um programa conhecido como Energeticismo (também chamado de Energética), um programa científico-filosófico centrado na ideia de energia e nas leis que descrevem as suas transformações, e contrário ao uso de entidades inobserváveis e indetectáveis através da experimentação, a exemplo dos átomos. ${ }^{9}$

Além de Ostwald, o programa energeticista tinha como defensores cientistas como Pierre Duhem (1861-1916), Georg Helm (1851-1923) e Henri Louis Le Châtelier (1850-1936), mesmo havendo divergências entre suas respectivas abordagens energeticistas. ${ }^{10}$ Contudo, Ostwald figurou como o principal representante da tentativa de desenvolver uma nova ciência, baseada na energia e suas leis e na substituição do paradigma mecanicista na química e demais ciências. ${ }^{10,11}$ A visão de mundo e o programa energeticista de Ostwald foram apresentados no artigo Die Überwindung des wissenschaftlichen Materialismus (A Superação do Materialismo Científico), publicado em $1895 .^{12}$

O programa energeticista sofreu duras críticas dos físicos Ludwig Boltzmann (1844-1906) e Max Planck (1858-1947). Esses físicos atacaram duramente as ideias energeticistas de Ostwald e Helm em um debate realizado em Lübeck em 1895, contribuindo para a rejeição e gradativo abandono do Energeticismo pela comunidade científica. ${ }^{13}$ Entretanto, Ostwald manteve a sua crença nas ideias energeticistas até o fim de sua vida, incorporando-a ao seu trabalho filosófico.

Em 1908, convencido da importância da teoria atômica pela descoberta de fenômenos como o movimento browniano e investigações como as realizadas por Joseph Thomson e Jean Perrin, Ostwald reconheceu o atomismo como uma teoria científica válida. Tal reconhecimento foi publicamente apresentado no prefácio do seu livro Grundriss der allgemeinen Chemie (Fundamentos de Química Geral, $4^{a}$ edição, 1909), ao afirmar que tais pesquisas "justificaram que o mais cauteloso dos cientistas fale agora em comprovação experimental da natureza atômica da matéria."14

O reconhecimento do valor científico da teoria atômica por Ostwald é apresentado como uma conclusão à controvérsia atômica ocorrida entre os séculos XIX e XX em artigos e livros escritos por educadores químicos. ${ }^{5,15-17}$ Entretanto, poucos trabalhos destacam que Ostwald continuou defendendo os fundamentos filosóficos do 
energeticismo e os conciliou com o atomismo nos últimos anos de sua vida, ao sugerir que as teorias físicas do início do século $\mathrm{XX}$, como a ideia de quantum e a Equivalência Massa-Energia proposta por Einstein, representariam uma espécie de síntese entre as perspectivas atomista e energeticista. ${ }^{18}$

Tais trabalhos sobre a controvérsia atômica que retratam Ostwald como um dos perdedores dos debates sobre o atomismo no início do século XX, ou sua conversão como um marco para o fim da controvérsia atômica, são permeados, ainda que tacitamente, por uma interpretação whig da história da química. A história whig caracterizase por uma visão presentista dos eventos do passado, ao descartar a complexidade e temporalidade deles, e uma visão maniqueísta dos personagens históricos, retratados ou como progressistas ou como retrógrados. ${ }^{19}$ Nesse sentido, a interpretação whig do papel de Ostwald na controvérsia atômica o apresenta como um cientista reticente às vantagens da abordagem atomista, assim como retrata, mesmo que de forma tácita, sua aceitação ao atomismo como a derrota do energeticismo e o triunfo da teoria atômica na ciência. Tal abordagem é comum aos escritos mais antigos sobre a história da ciência, mas ela ainda é reproduzida irrefletidamente por aqueles que buscam o apoio da história para fins didáticos.

É importante destacar que a visão maniqueísta da controvérsia atômica foi tão perniciosa para a reputação científica de Ostwald, que ele é considerado por alguns como responsável indireto pelo suicídio de Boltzmann. Esse mito, que não é corroborado por nenhuma fonte confiável, ainda é encontrado no discurso anedótico de professores em salas de aula, livros-texto e textos sobre a história das ciências..$^{20-23}$

Mesmo que o Energeticismo seja uma parte indissociável da história de Ostwald, reduzir a sua trajetória ao antiatomismo é ignorar o importante papel que este químico desempenhou na ciência de seu tempo. Ostwald contribuiu para a organização e popularização da Físico-Química, defendendo a autonomia e a importância deste campo de pesquisa. Ele também foi um pesquisador criativo e dinâmico, cujos êxitos e fracassos nos ensinam importantes lições sobre a produção do conhecimento científico, o desenvolvimento da Físico-Química e a incorporação desta ciência pela indústria química alemã no final do século XIX e início do XX.

Neste trabalho, apresentaremos alguns elementos da biografia de Wilhelm Ostwald para além da controvérsia atômica. Pretendemos demonstrar algumas de suas contribuições para o campo da FísicoQuímica, como suas pesquisas sobre afinidade química e diluição dos ácidos, suas ações para a organização e popularização da FísicoQuímica, a exemplo dos seus trabalhos literários e pedagógicos, suas investigações sobre a catálise. Também analisaremos suas sucessivas indicações ao Prêmio Nobel de Química a fim de termos uma medida da sua reputação entre os cientistas de sua época.

\section{DAS AFINIDADES À LEI DE DILUIÇÃO DOS ÁCIDOS}

A Teoria de Afinidade Química é originária dos antigos conhecimentos práticos sobre o comportamento químico da matéria que, no início do século XVIII, foram incorporados à interpretação mecanicista da natureza. ${ }^{24}$ Enquanto uma ferramenta teórica, as afinidades serviam para prever e explicar a ocorrência de alguns tipos de reações, assim como permitiam sistematizar as diversas reações químicas conhecidas com base nas forças relativas entre os diferentes compostos químicos, como nas Tabelas de Afinidade Química, instrumentos que organizavam as substâncias químicas de acordo com a intensidade das afinidades relativas entre diferentes substâncias..$^{24,25}$

Com o desenvolvimento da Termoquímica e Eletroquímica no século XIX, os químicos interessados nas afinidades químicas direcionaram seus estudos às relações de energia, e os conceitos de força e afinidade, oriundos da tradição newtoniana, foram substituídos pelo conceito de calor e, posteriormente, pelos conceitos termodinâmicos de energia e trabalho. ${ }^{26,27}$ Além disso, o crescente interesse pela química orgânica contribuiu para o estudo de reações reversíveis, o que despertou a atenção dos químicos para a influência de fatores físicos como massa, pressão e temperatura sobre a velocidade e o equilíbrio das reações químicas e, consequentemente, sobre as afinidades químicas dos reagentes. ${ }^{27,28}$ Portanto, o estudo de processos químicos reversíveis e as novas abordagens oriundas da Termoquímica e Eletroquímica contribuíram para uma nova forma de compreensão das afinidades e determinação quantitativa das mesmas; ao relacioná-las a propriedades físicas da matéria e, posteriormente, a grandezas termodinâmicas. É nesse contexto que surgem os primeiros trabalhos de Ostwald.

Oriundo de uma família alemã, Wilhelm Ostwald nasceu na cidade de Riga, atual Letônia, em 1853. Ostwald foi educado em uma escola religiosa com orientação técnica, o que contribuiu para despertar seu interesse por ciências e seu posterior ingresso no curso de Química na Universidade de Tartu (atual Estônia) em 1872.

Enquanto nos grandes centros científicos europeus predominava a pesquisa em Química Orgânica, o curso de Química da Universidade de Tartu seguia estritamente a tradição da Química Analítica e Inorgânica. Em Tartu, Ostwald foi orientado pelo químico Carl Schmidt (1822-1894), interessado em análise de minerais, e seu assistente, Johann Lemberg (1842-1902), a quem é creditado o contato de Ostwald com o tema da afinidade química. Ostwald também teve contato próximo com o físico Arthur von Öttingen, responsável por introduzi-lo ao estudo da termodinâmica. ${ }^{29}$

Em 1877, Ostwald apresentou seu trabalho de mestrado, intitulado Volumchemische Studien über Affinität, no qual apresentou o método volumétrico para medida das afinidades químicas. Instigado pelos trabalhos de Julius Thomsen (1826-1909), que estabelecera uma relação entre a afinidade química e o calor liberado em reações exotérmicas, Ostwald considerou que não apenas o calor, mas também outras propriedades da matéria, poderiam ser utilizadas para avaliar as afinidades relativas das substâncias químicas.

Entusiasmado com essa ideia, Ostwald elaborou um método para determinar as afinidades relativas de pares de ácidos frente a diferentes bases e temperaturas a partir da variação entre o volume final do sistema e a soma dos volumes dos reagentes, tendo também adaptado o picnômetro de Sprengel (conhecido hoje como picnômetro de Sprengel-Ostwald) para a medida das densidades relativas das substâncias envolvidas no experimento. ${ }^{30}$ Em seu doutorado, Ostwald comparou seu método volumétrico a outro também proposto por ele, o qual estabelecia as afinidades relativas dos ácidos a partir dos seus índices de refração. Contudo, ele concluiu que esse método não era tão generalizável, acessível e simples quanto o volumétrico. ${ }^{31}$

Os valores de afinidade química obtidos para alguns ácidos pelo método volumétrico de Ostwald apresentavam semelhanças com os valores de condutividade equivalente (hoje chamada de condutividade molar) encontrados pelo químico Friedrich Kohlrausch (1840-1910), mas Ostwald não foi capaz de explicar tal semelhança. ${ }^{32}$

O método volumétrico tornou Ostwald conhecido na comunidade científica ainda aos 26 anos de idade. Em 1881, Ostwald se tornou professor no Instituto Politécnico de Riga, onde continuou investigando a afinidade química de ácidos e bases, assim como a cinética e o equilíbrio de reações químicas. ${ }^{18}$

Contudo, outros jovens químicos também estavam investigando as afinidades químicas. Um deles foi o sueco Svante Arrhenius, estudante de doutorado na Universidade de Uppsala. Em sua tese, Arrhenius mostrou que a força dos ácidos era diretamente proporcional à condutividade dessas substâncias em solução. ${ }^{33}$ Ele propôs que, para que as moléculas conduzissem corrente elétrica, era necessário que 
elas estivessem em um estado apto para tal, chamado por ele de estado ativo. Arrhenius também afirmou que essas moléculas em estado ativo seriam as responsáveis pela afinidade química dos ácidos em solução, visto que ácidos fortes, isso é, de maior afinidade química frente a um reagente definido, apresentavam maior condutividade. Todavia, ele não conseguiu explicar quais condições despertariam o estado ativo das moléculas. ${ }^{33,34}$

O trabalho de Arrhenius foi mal recebido pelos seus orientadores, que atribuíram à sua tese uma nota mediana, com a qual dificilmente conseguiria uma posição nas universidades nórdicas. Buscando opiniões diferentes sobre os resultados do seu trabalho, ele enviou cópias de sua tese para vários químicos na Europa, dentre os quais, Ostwald.

Ostwald percebeu que os resultados de Arrhenius guardavam semelhança com seus valores de afinidade obtidos pelo método volumétrico, o que o levou a reconhecer o valor do trabalho do jovem químico sueco:

\begin{abstract}
“(...) o que ele escreveu era tão contrário a tudo até então conhecido e aceito que, em um primeiro momento, eu pensei que não fazia sentido. Mas então eu vi que o jovem autor tinha apresentado alguns cálculos da afinidade química dos ácidos que concordavam com os valores que eu havia alcançado a partir de uma abordagem totalmente diferente. Finalmente, tendo lido o trabalho em detalhes eu me convenci que este jovem tinha abordado os problemas da relação entre os ácidos e bases (...) de um modo muito mais acessível e tinha, em alguma extensão, resolvido parte deles." 35
\end{abstract}

Em vez de considerar Arrhenius um adversário, Ostwald optou por colaborar com o colega sueco, estabelecendo uma duradoura amizade entre ambos. Após um período de intensa correspondência entre eles, Ostwald o visitou em Uppsala no verão de 1884 e fez o possível para defender as ideias de seu novo colega. ${ }^{34}$ Por outro lado, Arrhenius despertou em Ostwald o interesse pelos estudos eletroquímicos, em especial, o comportamento elétrico dos ácidos e sua relação com a afinidade química dos mesmos, como veremos mais adiante.

Neste mesmo período, o holandês Jacobus Henricus van't Hoff, um químico que já havia conseguido notoriedade pelas suas contribuições à química orgânica, direcionou seu interesse para a análise do equilíbrio químico. Aplicando a Termodinâmica fenomenológica às reações em equilíbrio, ele deduziu que as forças de afinidade química eram equivalentes à quantidade de trabalho realizado por uma reação química. ${ }^{27}$ Seu trabalho foi apresentado na obra Études de dynamique chimique (1884). ${ }^{36}$

Após algumas correspondências, Ostwald, Arrhenius e van't Hoff estabeleceram uma relação de trabalho e amizade. A interação entre eles contribuiu para o estabelecimento da base teórico-conceitual e metodologias empregadas pela físico-química moderna, a exemplo da teoria de dissociação eletrolítica proposta por Arrhenius em 1887.

Investigando a pressão osmótica de soluções, van't Hoff percebeu que quanto maior o grau de dissolução, maior a pressão exercida pela solução em uma membrana semipermeável. Contudo, ele também percebeu que, dadas as mesmas condições, eletrólitos fortes, como ácidos inorgânicos, exerciam uma pressão maior do que não-eletrólitos, como o açúcar. ${ }^{34,37}$ Analisando os resultados de van’t Hoff, Arrhenius propôs que a maior pressão exercida pelos eletrólitos fortes poderia ser explicada assumindo que essas substâncias se dissociassem em água, formando partículas eletricamente carregadas

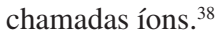

Alguns elementos que originaram a teoria de dissociação eletrolítica se encontram na tese de 1884 de Arrhenius, como sua controversa hipótese das moléculas ativas. Contudo, é equivocado afirmar que a teoria de dissociação eletrolítica já estivesse presente nesse trabalho. A ideia de íons enquanto constituintes da matéria parecia circundar a atmosfera intelectual da época. No mesmo ano em que Arrhenius publicou sua teoria, o físico Max Planck (18581947) publicou um trabalho no qual defendia a existência dos íons em solução a partir de um tratamento termodinâmico de dados crioscópicos. ${ }^{39}$ Também é importante destacar o trabalho de outros cientistas que abriram caminho para a teoria de Arrhenius, como Michael Faraday (1791-1867), responsável por diversas investigações eletroquímicas e por cunhar o termo íon, e Kohlrausch, que relacionou a condutividade molecular à diluição infinita $\left(\Lambda_{\infty}\right)$ à mobilidade dos íons presentes em uma solução. ${ }^{32,40}$

Até a divulgação da teoria de Arrhenius em 1887, acreditavase que os íons eram formados apenas com a passagem de corrente elétrica nas soluções eletrolíticas. Entretanto, as sólidas evidências experimentais, como os valores de pressão osmótica determinados por van't Hoff, a mobilidade dos íons de Kohlrausch, e relação entre condutividade e força dos ácidos e bases demonstrada por Arrhenius reforçaram a proposta de que os íons seriam constituintes da matéria, assim como átomos e moléculas. ${ }^{34,38}$

Apesar da teoria de dissociação eletrolítica ter gerado muita polêmica, ela foi aceita com relativa rapidez. Uma das razões foi o empenho de Ostwald em popularizar a teoria de Arrhenius; tanto por meio de suas ações como educador e divulgador da ciência, quanto por meio de suas pesquisas, ao adotar a teoria de dissociação eletrolítica como fundamento teórico de seus trabalhos. ${ }^{41}$

Desde o contato com Arrhenius em 1884, Ostwald havia incorporado a abordagem eletroquímica ao seu estudo sobre afinidades, desenvolvendo e adaptando métodos e instrumentos à sua pesquisa, a exemplo da célula de condutância e o banho termostático. ${ }^{32}$ Esses instrumentos foram utilizados em seu estudo sobre condutividade de ácidos fracos e moderados, que conduziram à formulação da lei de diluição dos ácidos, também conhecida como lei de diluição de Ostwald.

Os estudos que envolvem a proposição da Lei de Diluição foram apresentados em diferentes artigos publicados em 1888 no Zeitschrift für Physikalische Chemie, periódico fundado e editado por Ostwald, o qual discutiremos na seção seguinte. ${ }^{42,43}$ No primeiro desses artigos, Ostwald deduz a Lei de Diluição dos Ácidos partindo dos trabalhos de Arrhenius, van't Hoff e Planck, que mostraram que os eletrólitos em solução seguem leis semelhantes àquelas dos gases. Assim, utilizando as relações de van't Hoff para a dissociação de um eletrólito HX, tem-se que:

$$
\mathrm{P} / \mathrm{p}^{2}=\mathrm{C}
$$

em que $\mathrm{P}$ é a pressão exercida pela parte não-dissociada, p é a pressão exercida pelos íons dissociados e $\mathrm{C}$ é uma constante. As pressões $\mathrm{P}$ e $\mathrm{p}$ são diretamente proporcionais às massas da parte não-dissociada (U) e dissociada (u), e inversamente proporcionais ao volume de diluição da solução (v). Assim, a equação pode ser reescrita da seguinte forma:

$$
\text { U.v } / \mathrm{u}^{2}=\mathrm{C}
$$

Arrhenius mostrou ser possível encontrar $U$ e $u$ a partir das medidas de condutividade. Desse modo, sendo $\Lambda_{v}$ é a condutividade molecular da solução e $\Lambda_{\infty}$ a condutância em diluição infinita, tem-se a Lei de Diluição de Ostwald:

$$
\mathrm{v} .\left(\Lambda_{\infty}-\Lambda_{\mathrm{v}}\right) / \Lambda_{\mathrm{v}}^{2}=\mathrm{C}
$$

É importante destacar dois aspectos dessa lei. Primeiramente, Ostwald apresentou sua lei de diluição em um artigo de duas páginas, 
sem se referir a qualquer resultado experimental, fato ressaltado pelo próprio Ostwald. A validação experimental dessa lei foi apresentada em um segundo artigo, também publicado em 1888 no Zeitschrift, no qual Ostwald analisa a condutividade de ácidos fracos após diluições sucessivas. $^{43}$

Em segundo lugar, a equação (3) não representa a forma hoje conhecida como lei de Ostwald. No mesmo artigo em que Ostwald apresenta seus dados experimentais, ele introduziu o coeficiente de atividade $\left(\alpha=\Lambda_{\mathrm{v}} / \Lambda_{\infty}\right)$ proposto por Arrhenius. Assim, a lei de Ostwald pode ser reescrita como:

$$
\mathrm{K}=\alpha^{2} /(1-\alpha) . \mathrm{v}
$$

Por fim, apesar da lei de diluição ter sido reconhecida como uma de suas grandes contribuições de Ostwald para a Físico-Química e um exemplo da solidez da teoria de dissociação eletrolítica, essa lei possui limitações significativas. A lei de diluição se limita ao caso de soluções de monoácidos e monobases, assim como não descreve o comportamento de eletrólitos fortes, que constituem a maior parte dos ácidos, bases e sais inorgânicos.

Essa limitação foi apontada por alguns contemporâneos de Ostwald, mas foi ignorada ou considerada uma anomalia pelos físico-químicos, que não estavam dispostos a questionar a teoria de dissociação eletrolítica e as leis derivadas da mesma. ${ }^{39} \mathrm{O}$ comportamento dos eletrólitos fortes só foi descrito no início do século XX, pelos físicos Peter Debye (1884-1966), Erich Hückel (1896-1980) e Lars Onsager (1903-1976), que deram um tratamento matemático ao problema levando em consideração as interações entre os íons e as moléculas do solvente, o efeito de assimetria e o movimento browniano. ${ }^{44}$

\section{ENSINANDO E POPULARIZANDO A FÍSICO-QUÍMICA}

Poucos cientistas tiveram uma trajetória tão fortemente marcada por trabalhos de natureza pedagógica quanto Ostwald. O legado de Ostwald como educador e difusor do conhecimento químico pode ser percebido em seus diversos livros, no relato de seus ex-alunos, e nas suas ações em prol da comunicação científica no final do século XIX.

Ostwald foi autor de 45 livros, dentre os quais encontram-se manuais, textos sobre a história da química, biografias, escritos filosóficos e livros-texto, escritos que se somam ao trabalho como editor de periódicos e à escrita de artigos, resenhas e panfletos. ${ }^{45}$ O estímulo para a produção dessa extensa bibliografia parece ter vindo dos anos em que passou na Universidade de Tartu. Foi o seu orientador Carl Schmidt quem sugeriu a Ostwald, aparentemente em tom de brincadeira, a escrita de um livro-texto de Química. ${ }^{29}$ Contudo, Ostwald acabou levando a sugestão a sério, iniciando em 1880 a escrita do seu primeiro livro-texto.

Durante os anos em estudou em Tartu, Ostwald atuou como assistente de Schmidt e do físico Arthur von Öttingen. Seu trabalho consistia em ministrar algumas aulas e preparar e executar experimentos para turmas de graduandos. Mas o casamento com Helene von Reyher em 1879 e o nascimento do seu primeiro filho exigiram de Ostwald a busca por um emprego melhor. Graças à indicação de Schmidt, ele foi contratado em 1880 como professor de ciências e matemática em uma escola secundária em Tartu e, posteriormente, como professor de Química da Escola Politécnica de Riga em 1881. Segundo Ostwald, seu trabalho docente em Tartu foi importante para perceber a relevância do uso de uma linguagem simples e objetiva para o entendimento da química pelos seus alunos:

"Uma vez que meus alunos não tinham muita experiência nos assuntos, eu fui forçado a me limitar a um nível mais básico de explanação do que eu utilizava nas aulas da universidade e a experiência de fazer as coisas dessa maneira na escola, por sua vez, contribuiu para melhorar minhas aulas na universidade. Eu aprendi a importância da simplicidade e clareza na apresentação, e quando depois eu comecei a escrever livros-texto, estas foram qualidades pelas quais eles eram reconhecidos." ${ }^{46}$

Devido seu trabalho como professor, Ostwald conhecia os principais livros-texto de química de sua época. Essas obras, escritas por químicos importantes como Jöns J. Berzelius (1779-1848), Hermann Kopp (1817-1892) e Leopold Gmelin (1788-1853), poderiam fornecer para Ostwald um modelo de apresentação dos conteúdos. Entretanto, Ostwald se mostrava insatisfeito com os materiais disponíveis, que estavam há muito tempo obsoletos ou consistiam mais em compilações de artigos do que uma síntese didática do conhecimento químico. ${ }^{18}$ Contudo, ele estava consciente de que o trabalho literário e pedagógico era pouco valorizado pelos seus pares, incluindo seus professores Schmidt e Lemberg:

"Ambos desprezavam a escrita de livros e viam o coração da
ciência firmemente colocado em trabalhos experimentais que
deveriam ser descritos da maneira mais concisa e desapaixo-
nada possível. Nenhum deles reconhecia o valor de ordenar
e sistematizar o que já é conhecido para o avanço do saber,
embora haja numerosos exemplos nos quais publicações de
livros-texto trouxeram resultados de áreas díspares dentro de
um contexto e muitas vezes tornaram possível o desenvolvi-
mento de um campo." 47

Além do intuito de escrever um livro que fosse, de fato, didático, Ostwald pretendia organizar o conhecimento produzido e divulgar suas próprias pesquisas sobre afinidade química. Com tais objetivos, Ostwald publicou entre 1885 e 1887 o Lehrbuch der allgemeinen Chemie (Livro de Química Geral), ${ }^{48,49}$ obra dividida em dois volumes na qual Ostwald incorpora diferentes campos de pesquisa ao guardachuva disciplinar da Físico-química, a exemplo da Eletroquímica, a Termoquímica e a Fotoquímica. ${ }^{50}$

Além de divulgar suas pesquisas sobre afinidade química no Lehrbuch, Ostwald também introduziu em seu livro a tese de Arrhenius e os trabalhos termodinâmicos de van't Hoff, ajudando a divulgar o trabalho destes químicos em círculos científicos mais amplos em um período no qual eles ainda não haviam se tornado conhecidos. Do mesmo modo, Ostwald divulgou a teoria de dissociação eletrolítica - e seus trabalhos derivados da mesma - em seu livro-texto mais popular, o anteriormente citado Grundriss der allgemeinen Chemie (1889), obra traduzida para vários idiomas (inglês, russo, húngaro, japonês, espanhol e outros) que contribuiu para a popularização da Físico-Química ionista. ${ }^{18,51}$

Além de ser reconhecido por seus escritos pedagógicos, Ostwald também é lembrado por ter sido um cientista-historiador, tendo escrito obras sobre o desenvolvimento da química como Elektrochemie: ihre Geschichte und Lehre ${ }^{52}$ (Eletroquímica: sua História e Ensino, 1896) e organizado a coletânea de livros Klassiker der exakten Wissenschaften (Clássicos das Ciências Exatas), uma compilação de importantes artigos científicos organizados por áreas do conhecimento. ${ }^{53}$ Entretanto, Ostwald não possuía a história em si como principal motivação, mas sim a potencial utilidade desta para a compreensão das ideias científicas. Para ele a história não seria uma ciência, "mas meramente um método ou ferramenta que pode ajudar a alcançar o entendimento científico de certas questões." ${ }^{54}$

Em seus livros, Ostwald utilizava uma abordagem histórica para apresentação e organização dos conteúdos químicos. Ele acreditava 
que a História da Química refletia o desenvolvimento lógico dessa ciência e, portanto, essa abordagem seria a forma mais adequada para expor teorias, conceitos e descobertas científicas. ${ }^{48}$ Refletindo o espírito de sua época, a abordagem de Ostwald partia de uma concepção positivista de ciência, que entendia o passado da Química como uma marcha linear e cumulativa para um conhecimento cada vez mais objetivo e verdadeiro sobre o mundo. ${ }^{55}$

Controvérsias e análises pessoais de eventos não eram, contudo, excluídas das obras de Ostwald. Usando a escrita em primeira pessoa, Ostwald apresentou as pesquisas que realizou ou acompanhou em livros como o Lehrbuch e o Grundriss, assim como também deixava evidente sua opinião sobre assuntos controversos como a realidade atômica e a abordagem energeticista, tendo inclusive dedicado uma parte da segunda edição do Lehrbuch (1893) para apresentar os fundamentos do Energeticismo.

Ostwald também escreveu para o público leigo, com o objetivo de popularizar a química e introduzir noções básicas sobre esta ciência. Em seu livro Schule der Chemie, ele apresenta conceitos e teorias químicas por meio de uma narrativa em forma de diálogo entre um professor e seu aluno - um recurso narrativo já utilizado por outros autores, como o próprio Galileu Galilei. Esse livro foi publicado em dois volumes em 1903 e 1904 e traduzido para vários idiomas. ${ }^{56,57}$

Somado ao trabalho de escritor, Ostwald dedicou boa parte de sua carreira à edição de periódicos, um tipo de literatura em expansão em sua época. Historiadores afirmam que o número de periódicos científicos existentes no mundo cresceu de 100 títulos para cerca de 10 mil ao longo do século XIX. ${ }^{58}$ Tal proliferação deveu-se não apenas ao crescimento do mercado editorial. As diversas descobertas da Química oitocentista tornavam os periódicos cada vez mais necessários para desenvolvimento de uma ciência que estava se tornando mais especializada e geograficamente descentralizada. ${ }^{3}$

A expressão físico-química surgiu muito antes ao século XIX, sendo utilizada por filósofos naturais como Andreas Libavius (15401616) e Robert Boyle (1627-1691). Porém, de acordo com o historiador Thomas Hapke, o termo "físico" nesse contexto referia-se ao conceito aristotélico de física, isto é, o conhecimento acerca do mundo natural. ${ }^{59}$ Foi na década de 1880 que a Físico-Química, compreendida então como um campo do saber que articula saberes, objetos e abordagens da Física e da Química, alcançou o status de disciplina autônoma. ${ }^{44}$ Foi no último quartel do século XIX que surgiu uma comunidade de cientistas que se identificavam como físico-químicos, assim como surgiram institutos, cátedras e periódicos dedicados a essa disciplina. $\mathrm{O}$ primeiro desses periódicos foi o Zeitschrift für Physikalische Chemie, fundado por Ostwald e van't Hoff em 1887.

Uma das motivações para a criação do Zeitschrift foi a dificuldade e o pouco destaque dado aos trabalhos de Físico-Química nos periódicos de química existentes, mas apesar do reconhecimento destes problemas por Ostwald e seus pares, havia o receio de que um jornal desta natureza não se sustentasse pelo supostamente restrito número de interessados em trabalhos físico-químicos, como sugerido por alguns interlocutores de Ostwald. ${ }^{18,59}$

A despeito das dúvidas quanto ao sucesso do projeto, Ostwald e o editor e astrônomo Rudolf Engelmann (1841-1888) acertaram a publicação de um periódico especializado nessa disciplina, sob chefia do primeiro. Apesar de constar como co-editor do Zeitschrift, van't Hoff não desempenhou papel ativo na criação deste periódico de acordo com Ostwald, tendo "colaborado" apenas com sua reputação: como van't Hoff construiu uma carreira na Química Orgânica alguns anos antes, sendo conhecido para além da comunidade de físicoquímicos, seu nome poderia atrair mais leitores para o recém-fundado periódico. ${ }^{18}$ Desse modo, editado por Ostwald e, em tese, por van't Hoff, o Zeitschrift für Physikalische Chemie publicou seu primeiro número em fevereiro de 1887.
O primeiro número do Zeitschrift contou com trabalhos de diversos químicos que haviam sido convidados por Ostwald para publicar no novo periódico. Entre os autores do primeiro número encontramos químicos de diferentes países, mostrando não apenas o caráter internacional da comunidade de físico-químicos, mas também a ausência de comunidades locais. Em seu primeiro editorial, Ostwald defendeu que o jornal não se restringia aos praticantes da físico-química, mas a todos os químicos, independentemente de sua especialidade. De acordo com Ostwald, a Físico-Química seria uma disciplina de interesse geral e "nenhum químico que leva a sério sua ciência, especialmente nenhum professor, pode ignorá-la."60

No mesmo editorial, Ostwald destacou que o objetivo principal do Zeitschrift era publicar trabalhos físico-químicos experimentais. Tal objetivo foi alcançado, visto que importantes trabalhos físicoquímicos foram publicados no Zeitschrift, como os já citados trabalhos de Arrhenius e van't Hoff, as pesquisas de William Ramsay (18521916) sobre gases inertes e os estudos eletroquímicos de Walther Nernst (1864-1941), por exemplo. Contudo, Ostwald também deixou claro que havia espaço em seu jornal para discussões teóricas e proposição de hipóteses, desde que elas se baseassem em fatos empíricos. ${ }^{61}$ Tal espaço para discussões teóricas foi bem aproveitado por Ostwald, que travou diversos debates sobre a natureza da catálise, a abordagem energeticista e o atomismo nas páginas do Zeitschrift.

Ostwald também foi editor de outros periódicos e revistas, como o Zeitschrift für Elektrochemie (Revista de Eletroquímica, 1894), publicação também dedicada à Físico-Química; o Annalen der Naturphilosophie (Anais de Filosofia Natural, 1901), publicação dedicada à filosofia natural e filosofia da ciência; e o Das monistische Jahrhundert (O Século Monista, 1912), revista da Liga Monista Alemã, voltada à temas como política, cultura e filosofia.

O reconhecimento de Ostwald como figura central no processo de institucionalização da Físico-Química não se limita, entretanto, à sua extensa bibliografia ou ao seu papel na fundação de periódicos científicos. Outro elemento a se considerar é o seu papel enquanto professor, ou seja, sua influência na formação de jovens físico-químicos.

Os primeiros estudantes surgiram enquanto ele ainda era professor da Escola Politécnica de Riga, a exemplo do químico russo-letão Paul Walden (1863-1957), mas foi a partir de 1887, quando Ostwald assumiu a cátedra de Físico-Química na Universidade de Leipzig, que sua reputação de educador alcançou círculos mais amplos.

Entre 1887 e 1906, ano em que se aposentou, Ostwald recebeu mais de 300 pesquisadores em seu laboratório, entre estudantes, pesquisadores visitantes e outros colaboradores, o que tornou o Laboratório de Físico-Química da Universidade de Leipzig o mais importante centro de formação de físico-químicos do mundo até o início do século XX. . $^{28,62}$

Ostwald foi responsável pela formação de importantes cientistas, a exemplo do químico Gilbert Newton Lewis (1875-1946), que relatou ter se sentido bastante estimulado durante seus estudos em Leipzig devido ao contato com Ostwald. ${ }^{63}$ Outro exemplo da sua reputação nos é apresentado pelo físico Albert Einstein (1879-1955), que pediu uma vaga no laboratório de Ostwald para que pudesse obter uma "formação adicional." " Ostwald também era reconhecido no Brasil: o engenheiro e professor luso-brasileiro Álvaro Soares Brandão (1891-1963) enviou uma cópia do seu livro Chimica (1928) para Ostwald, pedindo sua opinião sobre a obra. ${ }^{65}$ Contudo, pelo que pudemos verificar em arquivos, Ostwald não respondeu ao colega brasileiro.

Há muitos relatos sobre Ostwald enquanto professor e orientador produzidos pelos seus ex-alunos. Tais relatos, obviamente, precisam ser vistos com cautela, pois muitas vezes nos oferecem uma visão distorcida, muitas vezes romantizada, do trabalho docente de Ostwald. 
Apresentaremos aqui, quando possível, evidências que apoiem - ou refutem - tais memórias.

Ostwald é lembrado como um pesquisador criativo e de fácil acesso pelos seus ex-alunos. Alguns relatos o apontam como responsável pela proposição de alguns dos temas das pesquisas de seus orientandos. ${ }^{62}$ A presença ativa de Ostwald em seu laboratório foi retratada pelo seu ex-aluno, o químico estadunidense Harry Jones (1865-1916), da seguinte maneira:

"A fertilidade da mente de Ostwald para novas ideias nunca deixou de impressionar qualquer um que esteve com ele mesmo que por um curto período, e também a não-usual liberdade com a qual sugestões, frequentemente de grande relevância, eram feitas para qualquer um que tivesse o desejo e habilidade para trabalhar no laboratório. E quando o trabalho estava pronto, era dito ao estudante que publicasse a investigação como se todo o trabalho fosse apenas dele. $\mathrm{O}$ resultado é que uma grande parte do trabalho feito no laboratório de Ostwald não leva seu nome, embora a sugestão original viesse dele e toda etapa de investigação estivesse sob seu escrutínio diário.”66

Tal afirmação encontra respaldo em diversos artigos publicados por estudantes de Ostwald no Zeitschrift. Nesses artigos, Ostwald não era incluído como um dos autores, mas é mencionado nos agradecimentos como responsável pela sugestão do tema de pesquisa. Um exemplo é encontrado no trabalho do químico russo Alexander Titow (1878-1961), que escreveu ao final de seu artigo: "ao meu estimado professor, W. Ostwald, eu expresso minha profunda gratidão pela sugestão do tema para este trabalho e a benevolência sempre dirigida a mim." ${ }^{67}$

Ao recordar o período em foi orientado por Ostwald, o químico russo George Jaffé (1880-1965) afirmou que todos os estudantes conheciam quais trabalhos que estavam sendo realizados no laboratório, afirmando que "não havia sensação de mistério no lugar, mas um espírito que Ostwald chamava de 'abertura fraternal'." 68 Jaffé também apresenta um relato do processo de condução das pesquisas por Ostwald:

"Havia um seminário semanal: 'Relatos sobre trabalhos científicos', não relatos sobre trabalhos científicos publicados na literatura, mas sobre o trabalho científico em andamento no próprio laboratório. Todas as pesquisas eram tratadas lá mais de uma vez. A primeira vez que um tópico era apresentado, o próprio Ostwald, ou um dos assistentes, expunha a linha que ele seguia. Na segunda vez, em geral, quando a pesquisa estava em andamento, o próprio pesquisador relatava seu trabalho. Nesta fase, ele tinha que expor principalmente as dificuldades que havia encontrado. Por fim, era apresentado um relatório sobre o artigo finalizado." ${ }^{68}$

Em nossa pesquisa, não encontramos registros dessas reuniões, mas o relato de Jaffé é semelhante a outros encontrados na literatura. Os químicos que trabalharam com Ostwald afirmaram em diferentes ocasiões que o seu laboratório era um ambiente propício a trocas de ideias e sugestões sobre os trabalhos em desenvolvimento. ${ }^{28,62}$

No final da década de 1890, após um período de exaustão e depressão, Ostwald começou a se afastar da pesquisa em Química e, consequentemente, desinteressou-se pelo trabalho docente. Após retornar dos Estados Unidos, onde atuou como professor visitante na Universidade de Harvard, Ostwald aposentou-se da Universidade de Leipzig em 1906, afastando-se da pesquisa em Físico-Química, mas adquirindo novos interesses em áreas diversas como filosofia, teoria das cores, Monismo, política e padronização científica.

\section{OSTWALD E A CATÁLISE: DA TEORIA À INDÚSTRIA}

Apesar do termo catálise ter sido cunhado em 1835, os fenômenos catalíticos eram conhecidos pelos filósofos naturais e químicos desde o século XVI. Algumas hipóteses sobre a natureza da catálise se baseavam em teorias mais gerais sobre a afinidade química, como a teoria dualista eletroquímica, enquanto outras tentavam explicar o fenômeno por meio do contato dos reagentes com o catalisador. ${ }^{69}$ Mesmo que alguns tenham tentado explicar a catálise, esse fenômeno não obteve destaque na agenda dos químicos até o início do século XX.

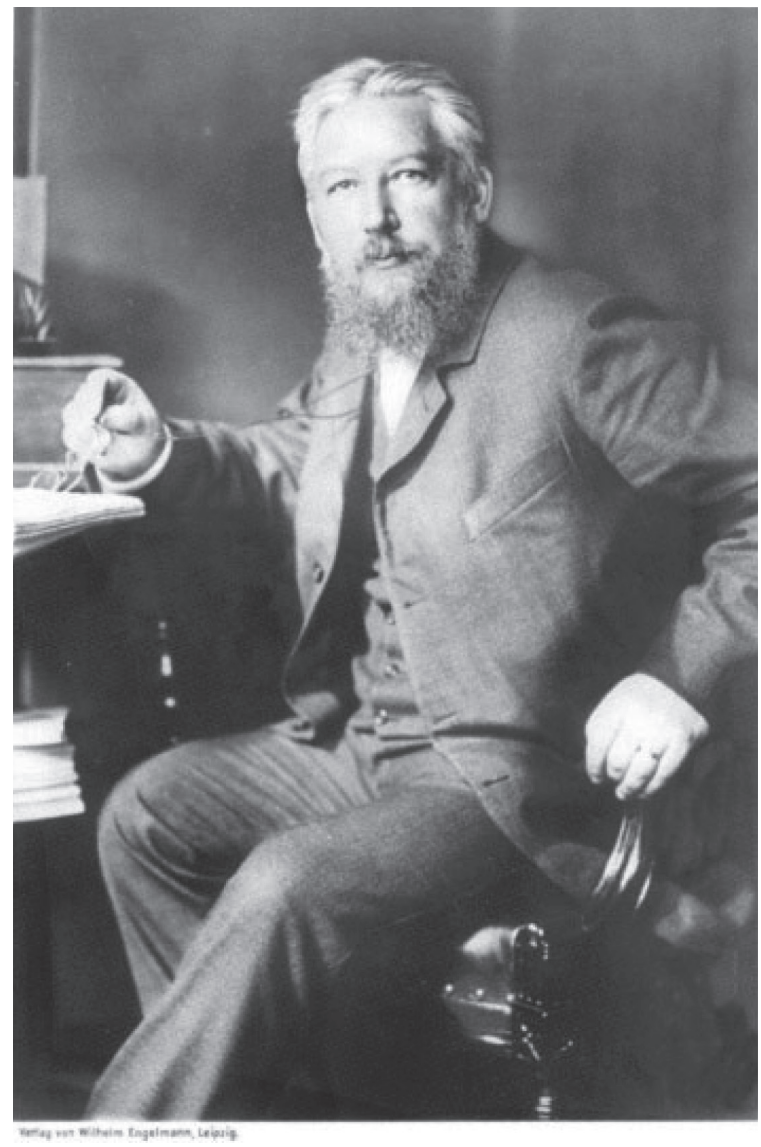

Figura 1. Fotografia de Wilhelm Ostwald publicada no Zeitschrift für Physikalische Chemie em homenagem ao seu aniversário de 50 anos (1903)

Um dos que estimularam tal mudança foi Wilhelm Ostwald (Figura 1). Apesar de ter realizado algumas pesquisas sobre o equilíbrio e velocidade química de reações catalíticas ainda em Tartu, o primeiro trabalho de Ostwald dedicado à catálise em si foi publicado em 1890. Ao analisar a conversão da solução de ácido $\gamma$-oxovalérico em valerolactona e perceber que os próprios íons hidrogênio resultantes da ionização do ácido $\gamma$-oxovalérico catalisavam a reação, Ostwald introduziu a expressão autocatálise, definida como a catálise de uma substância química por ela própria. ${ }^{70}$ Nos anos seguintes, a catálise se tornou um dos seus principais temas de pesquisa. Tal interesse deveu-se não apenas porque este tema era ainda pouco explorado, mas também porque esse campo poderia ser uma vitrine para a sua abordagem energeticista.

O Energeticismo, também chamado de Energética, foi um programa científico e, posteriormente, filosófico surgido no final do século XIX em oposição à ciência e visão de mundo mecanicista. Esse programa tinha como principal objetivo reformular e unificar as ciências em torno da ideia de energia e das leis fenomenológicas que descrevem as suas transformações. ${ }^{9,71}$ 
As raízes científicas do Energeticismo se encontram na Termodinâmica, em especial, no princípio de conservação da energia de Julius Robert von Mayer (1814-1878), e nas pesquisas termodinâmicas de Rudolf Clausius (1822-1888) e William Thomson (Lord Kelvin, 1824-1907). Epistemologicamente, o programa energeticista se aproxima das ideias positivistas do final do século XIX, rejeitando entidades inobserváveis e hipóteses que davam sustentação à importantes teorias científicas da época, como átomos e moléculas. Em contrapartida, os energeticistas propunham uma ciência fundamentada na experimentação e nas relações de energia entre os fenômenos. ${ }^{71}$

Apesar de sua relação com a Termodinâmica, o Energeticismo possui uma abordagem mais ampla, considerando algumas grandezas físicas, a exemplo do volume, como um tipo de manifestação de energia. ${ }^{9}$ Além disso, embora a primeira lei do Energeticismo guarde semelhança com a primeira lei da Termodinâmica, referindo-se à conservação da energia total de um sistema, a segunda lei do Energeticismo se baseia na grandeza intensidade energética, que representa as tendências inerentes às diferentes formas de energia em direção ao equilíbrio do sistema. ${ }^{9,72}$ Assim, a segunda lei do Energeticismo pode ser enunciada como: "se duas intensidades [energéticas] são individualmente iguais a uma terceira, elas são iguais entre si." ${ }^{33}$

Como já dissemos, a aceitação do Energeticismo por Ostwald é um tema popular na historiografia da ciência. Em sua autobiografia, Ostwald descreve a adoção deste paradigma como uma conversão espiritual, ${ }^{74}$ mas é possível compreender esse processo de maneira mais racional: a Termodinâmica fenomenológica e, em especial, os trabalhos de van't Hoff e Josiah Willard Gibbs (1839-1903) exerceram grande impacto no pensamento de Ostwald, mostrando ser possível compreender as transformações químicas a partir da análise das grandezas macroscópicas e leis termodinâmicas. ${ }^{9}$ Ao mesmo tempo, ideias antimaterialistas em voga nesse período, como o positivismo machiano, atraíam uma parte importante dos cientistas da época, que estavam desapontados com a ciência mecanicista, que parecia não dar conta de explicar fenômenos importantes - dentre os quais as transformações químicas - e se baseavam em entidades abstratas, como o éter e os átomos. ${ }^{75,76}$ Esses fatores desempenharam um papel importante na ruptura de Ostwald com a ciência mecanicista em favor de uma nova compreensão da realidade, baseada na centralidade da energia e nas leis que descrevem suas transformações.

A abordagem energeticista de Ostwald para a catálise baseia-se na premissa da energia como conceito central da ciência e no uso mesmo que apenas retórico - das leis do Energeticismo para descrição dos fenômenos catalíticos. Outra característica importante é a recusa em utilizar teorias cinético-moleculares, pois tais teorias, segundo Ostwald, baseavam-se em hipóteses sem fundamento empírico. ${ }^{9,18}$ Em contrapartida, ele defendia uma abordagem fenomenológica para a catálise, limitando-se ao que poderia ser obtido diretamente da experimentação e expresso em grandezas físico-químicas mensuráveis.

Esses princípios guiaram a elaboração de sua definição de catálise, publicada em 1894 no Zeitschrift für Physikalische Chemie. Em uma resenha sobre um trabalho do químico Friedrich Stohmann (18321897) que definira a catálise como "uma condição do movimento dos átomos em uma molécula de um corpo instável que resulta na entrada da energia emitida de um corpo para outro e leva à formação de corpos mais estáveis com perda de energia,"

"Primeiramente, a suposição de 'uma condição do movimento dos átomos em uma molécula' é hipotética e, portanto, não é adequada para fins de definição. Além disso, isso claramente não é uma perda de energia. E mais, ao descrever condições características de catálise, uma perda de energia livre pode ocorrer sob condições mesmo de captação absoluta de energia."78

Recusando-se ir além do fenômeno, Ostwald propôs uma definição fenomenológica para a catálise, compreendida como "a aceleração de uma reação química que ocorre lentamente, pela presença de uma substância estranha." ${ }^{78}$

O interesse de Ostwald em sistematizar a Química também o levou a propor uma forma de sistematização dos fenômenos catalíticos, organizados por ele em quatro grupos: catálise homogênea, quando os reagentes e o catalisador formam um sistema homogêneo; catálise heterogênea, quando os reagentes e o catalisador formam um sistema heterogêneo; catálise enzimática, que refere-se a ação das enzimas em sistemas biológicos; e a catálise de sistemas supersaturados, que refere-se à precipitação de solutos em soluções supersaturadas, compreendido por ele como um processo catalítico, mas que hoje não é entendido como tal. ${ }^{79}$

Se o Energeticismo ajudou Ostwald a ter um novo olhar sobre os fenômenos catalíticos, afastando-se das hipóteses corpusculares e cinéticas que não possuíam, de acordo com ele, fundamento empírico, esta abordagem, de certo modo, também o impediu de compreender melhor suas causas. Diferentes hipóteses foram propostas para explicar a ação dos catalisadores durante o século XIX, como a ocorrência de reações intermediárias ou catálise por contato, mas Ostwald recusava-se em apoiar completamente essas ideias ou propor explicações que transcendessem as evidências experimentais. ${ }^{50}$

Além de trabalhos teóricos, Ostwald se envolveu com a indústria química alemã. Muito se sabe sobre o papel de Fritz Haber e Carl Bosch para a síntese da amônia e sua produção em escala industrial, trabalhos que renderam a Haber e Bosch o prêmio Nobel de Química em 1918 e 1931, respectivamente. ${ }^{80}$ Contudo, é pouco mencionado o papel de Ostwald nos esforços para a produção industrial de amônia e outros compostos nitrogenados pela Alemanha, que importava da América do Sul matéria prima para produção dessas substâncias, o que tornava o processo caro e suscetível a problemas políticos. ${ }^{81,82}$

Muito bem informado quanto a literatura química de sua época, Ostwald conhecia o trabalho de César-Mansuète Despretz (1791-1863) que obteve os gases hidrogênio e nitrogênio a partir da decomposição da amônia pelo contato desta substância com um fio de ferro incandescente atuando como catalisador. Desse modo, Ostwald acreditava ser possível obter amônia a partir da reação inversa, aplicando deste modo as então recentes teorias de equilíbrio químico para o problema da síntese da amônia. ${ }^{18}$

O procedimento experimental submetido por Ostwald ao escritório de patentes envolvia o contato dos gases reagentes com um catalisador de ferro ou cobre, sob uma faixa de temperatura de 250 a $300{ }^{\circ} \mathrm{C}$, e contínua remoção da amônia produzida, a fim de favorecer o equilíbrio da reação para a formação dos produtos. ${ }^{18}$ Os primeiros resultados desta síntese entusiasmaram Ostwald: uma pequena quantidade de amônia foi detectada pelos seus assistentes Max Bodenstein e Eberhard Brauer, responsáveis pelo teste do procedimento. O sucesso inicial dos estudos preliminares fez com que Ostwald iniciasse negociações com indústrias como a Hoechst e a Badische Anilin \& Soda Fabrik (BASF), a fim de vender os direitos de utilização do processo. ${ }^{81}$

A direção da BASF designou um funcionário, o então jovem químico Carl Bosch (1874-1940), para confirmar a eficiência do método de Ostwald, Bodenstein e Brauer. Contudo, a análise de Bosch concluiu que a amônia obtida não era proveniente do gás nitrogênio, mas de traços dessa substância presentes em todos os catalisadores de ferro comerciais. ${ }^{83}$ Ostwald inicialmente não acreditou nas conclusões de Bosch, mas novos experimentos 
confirmaram que o jovem químico da BASF estava certo. ${ }^{81}$ Alguns anos depois, o químico Fritz Haber (1868-1934), então recémformado, consultou Ostwald sobre uma possível colaboração com indústrias austríacas interessadas em retomar as pesquisas sobre síntese da amônia. Contudo, ele ignorou o convite de Haber, que viria a sintetizar a amônia em 1909 a partir de um método que guardava alguma similaridade com o seu. ${ }^{84}$

Ostwald e Brauer retornaram novamente à pesquisa industrial poucos anos depois, propondo um método para produção de ácido nítrico a partir da oxidação da amônia utilizando um catalisador de platina. Dessa vez o processo foi bem sucedido. Ostwald tentou negociar com grandes indústrias como a BASF, Hoechst e Bayer, mas essas não concordaram com o valor exigido por Ostwald. ${ }^{85}$

Com o apoio financeiro do empresário alemão Max von Duttenhofer (1843-1903) e, após a morte dele, do industrial Bernhard Lepsius (1854-1934), Ostwald e Brauer conseguiram implementar uma fábrica para a produção de ácido nítrico e chegaram a produzir cerca de $300 \mathrm{~kg}$ desta substância por dia no ano de $1906 .{ }^{83}$ Contudo, alguns problemas impediram a popularização desse processo: o catalisador de platina utilizado era muito caro e pouco adequado às altas temperaturas necessárias para a oxidação. Além disso, a amônia, matéria-prima para a produção do ácido nítrico, ainda era uma substância difícil e cara de se obter. ${ }^{85}$

Por tais razões, a quantidade de ácido nítrico produzida por Ostwald e Brauer nunca chegou ao ponto de suprir a demanda do mercado alemão. Em 1914, a BASF implementou um processo desenvolvido por Alwin Mittasch (1869-1953) e Christoph Beck (1887-1960) para a produção de ácido nítrico a partir da amônia usando um catalisador mais barato, de óxido de bismuto, tornando o processo Ostwald-Brauer obsoleto poucos anos depois. ${ }^{81}$

\section{OSTWALD E O NOBEL DE QUÍMICA}

Durante o século XX, o Prêmio Nobel tornou-se uma das premiações científicas mais importantes e populares. Concebido pelo químico e inventor Alfred Nobel (1833-1896) em seu testamento, o prêmio celebra desde 1901 o trabalho de cientistas no campo da Física, Química, Medicina e Fisiologia, além dos prêmios em Literatura, Paz e Economia.

Em seus anos iniciais, o Nobel de Química tinha como objetivo aqueles que recentemente haviam feito relevantes descobertas ou melhorias nessa área, embora as vagas noções de "recente" e "melhoria" tenham sido pontos de debate entre os responsáveis pelo prêmio em algumas ocasiões. ${ }^{86} \mathrm{O}$ sistema de escolha dos vencedores também era bastante complexo. Em resumo, os candidatos deveriam ser indicados por nomeadores permanentes e convidados, que enviavam cartas de nomeação com os nomes de seus candidatos. As cartas eram analisadas e avaliadas por um comitê de premiação escolhido pela Academia, que após as deliberações sugeriam nomes para o prêmio. A decisão final era da Academia, que em reunião plenária decidia quem seriam os ganhadores. ${ }^{86}$

Em 1909, Ostwald recebeu o prêmio Nobel de Química. O reconhecimento pela Academia veio em um contexto peculiar: ele estava aposentado desde 1906, afastado da pesquisa em química e se dedicando a tópicos alheios a esta disciplina. Ostwald, que havia sido indicado continuamente ao prêmio desde 1904, afirmou ter ficado surpreso com o prêmio devido ao reconhecimento desse aos seus trabalhos sobre catálise, um campo no qual se dedicou em seus últimos anos em Leipzig, como vimos anteriormente. ${ }^{87}$

Alguns trabalhos defendem que a definição de catálise proposta por Ostwald foi o principal motivo para sua premiação em 1909. ${ }^{88,89}$ Contudo, os historiadores Elisabeth Crawford e Robert Friedman mostraram, a partir da análise de documentos como atas da premiação e correspondências pessoais, assim como uma análise do contexto científico sueco no início do século XX, que Ostwald recebeu o Nobel de Química devido às ações de Arrhenius nos bastidores da premiação..$^{85,90}$

Membro do comitê de premiação do Nobel de Física, Arrhenius exercia sua influência também sobre o prêmio de Química. ${ }^{11}$ Junto ao presidente do comitê de premiação do Nobel de Química, o químico Oskar Widman (1852-1930), Arrhenius conseguiu tornar Ostwald - que havia sido rejeitado durante cinco anos seguidos - um dos candidatos fortes da edição de 1909. Uma das ações de Arrhenius e Widman foi utilizar os trabalhos de Ostwald sobre catálise, que constituíam as suas pesquisas mais recentes, como um pretexto para sua indicação..$^{90}$

Os arranjos nos bastidores, entretanto, não são exclusivos do caso de Ostwald. Ademais, temos que considerar o fato de Ostwald ter sido apoiado durante seis ininterruptos anos ao prêmio, como mostram as cartas de nomeação enviadas ao comitê de premiação do Nobel de Química. Os nomeadores de Ostwald, entre os quais encontramos ex-alunos, colaboradores e admiradores do seu trabalho, destacam uma diversidade de razões pelas quais, segundo os mesmos, Ostwald deveria ser premiado. Apresentaremos aqui algumas delas.

Primeiramente, chama atenção o fato de muitos nomeadores não se limitarem a destacar trabalhos que se enquadrem nos critérios estabelecidos pelo prêmio. Não sabemos se isso ocorreu por desconhecimento do estatuto da premiação por parte dos nomeadores aqui citados, ou se havia insatisfação com as regras estabelecidas. O fato é que algumas das razões apresentadas a favor de Ostwald transcendem os critérios presentes no estatuto, mas nos mostram um panorama rico do seu legado e de sua reputação científica. ${ }^{50}$

Alguns nomeadores defenderam a candidatura de Ostwald por suas ações em prol do ensino e popularização da Química, chamando atenção para a importância de seus livros-texto, seu papel como organizador do conhecimento químico e suas ações para divulgação da Físico-Química. Os químicos Thorstein Hiortdahl (1839-1925) e Heinrich Goldschmidt (1857-1937), e os geologistas Waldemar Brøgger (1851-1940) e Johan Vogt (1858-1932) escreveram uma carta de nomeação coletiva, indicando Ostwald ao Prêmio Nobel de 1907 devido ao papel que seus livros desempenharam no ensino e popularização da Físico-Química:

“(...) o método de ensino na área da físico-química é quase exclusivamente trabalho de Ostwald (...) nos contentaremos em chamar atenção para seu grande 'Lehrbuch der allgemeinen Chemie' e seu 'Grundlinien der Chemie' [Fundamentos de Química]. A primeira edição do primeiro livro foi publicada no tempo em que os trabalhos de van't Hoff e Arrhenius não haviam sido publicados ainda e não eram conhecidos nos círculos mais amplos (...). Seu 'Grundlinien' trata a Química Inorgânica de uma nova forma, baseando-se na Físico-Química, e tem sido reconhecido como uma importante melhoria no campo da pedagogia do ensino de química."92

Em 1908, o químico suíço Emil Constam apresentou os méritos de Ostwald em sua carta de nomeação, destacando, dentre outros méritos, suas ações para a popularização da Físico-Química:

"Como nenhum outro contemporâneo, ele [Ostwald] desenvolveu o ensino e os métodos da Físico-Química para o benefício da pesquisa de químicos de todas as disciplinas químicas e educou um número surpreendente de estudantes que se tornaram professores universitários de destaque em vários países. Através de seus numerosos escritos e do 
'Zeitschrift für physikalische Chemie' fundado por ele, ele levou o conhecimento da química geral para os mais amplos círculos."93

O reconhecimento de tais ações por esses nomeadores é interessante, visto que atividades de natureza pedagógica geralmente desempenham um papel secundário na construção da reputação científica. Como vimos anteriormente, Ostwald afirmava que, de modo geral, seus pares consideravam atividades docentes como inferiores, incluindo seus próprios professores. Descobertas, metodologias e teorias eram - e ainda são - consideradas por alguns praticantes como os únicos produtos possíveis da atividade científica, ignorando outros trabalhos como aqueles com propósitos pedagógicos. Contudo, os apoiadores de Ostwald pareciam reconhecer a importância dos livros-texto e atividades de ensino na popularização de novas teorias e criação de comunidades científicas.

Além de êxitos no campo do ensino e divulgação da FísicoQuímica, alguns dos nomeadores de Ostwald também citaram sua atividade filosófica como razões para o prêmio. Um deles foi o químico estadunidense Theodore Richards (1868-1928), que o indicou ao Nobel de Química em 1905. Em sua carta de nomeação, Richards apresenta dois candidatos ao prêmio: Adolf von Baeyer (1835-1917), por suas pesquisas em síntese orgânica, e Wilhelm Ostwald, "pela sua influência geral no pensamento químico e pela sua abordagem filosófica do tema." ${ }^{4}$

Richards não explica no que consistia a abordagem filosófica de Ostwald, mas é possível conjecturar que ele se referia à amálgama entre Energeticismo, ciência e filosofia positivista que resultou em uma visão não-convencional sobre o mundo e o conhecimento científico. Sua crença na energia como conceito fundamental e sua rejeição à ciência mecanicista, isso é, uma ciência fundamentada na mecânica, o levaram a tentar reformular a Química, rejeitando o que ele considerava como metafísico. Em 1905, ano em que Richards o nomeou, ele ainda estava bastante engajado em demonstrar os problemas da química mecanicista e desenvolver uma abordagem energeticista para Química. ${ }^{95}$

Ostwald não foi nomeado apenas por trabalhos pedagógicos ou filosóficos. As cartas de nomeação mencionam uma série de pesquisas experimentais, além de melhorias em equipamentos e invenções realizadas por ele. Alguns destes equipamentos foram citados por Walden em sua carta de nomeação de 1904, como o picnômetro, o termostato, o viscosímetro, entre outros. ${ }^{96}$

A lei de diluição dos ácidos foi sua descoberta mais relevante de acordo com seus apoiadores, dada a frequência com que é citada nas cartas de nomeação. Por outro lado, suas pesquisas sobre catálise, utilizadas por Arrhenius e Widman para justificar sua premiação em 1909, não foram tão mencionadas nessas cartas. Outras investigações também foram citadas pelos seus apoiadores, como seus estudos eletroquímicos e cinéticos. Porém, é notório que, mesmo Ostwald tendo realizado diversas pesquisas físico-químicas, seus nomeadores não apresentem detalhes sobre esses trabalhos, mencionando-os de forma genérica em suas cartas.

A despeito do título deste trabalho, é preciso mencionar a relação entre o antiatomismo e a trajetória de Ostwald no Prêmio Nobel de Química. A literatura mostra indícios de que a aceitação do atomismo por Ostwald em 1908 contribuiu para que Arrhenius voltasse sua atenção à candidatura de seu colega. ${ }^{97}$ Contudo, assim como o Energeticismo, a rejeição de Ostwald ao atomismo também foi mencionada por alguns dos seus apoiadores, direta e indiretamente, como uma característica intrínseca a sua abordagem científica, não como um problema ou uma falha em seu trabalho. Enumerando os méritos de Ostwald, o químico estadunidense Arthur Noyes (18661936) afirmou que ele deveria ser nomeado pelo seu "vigoroso apoio às considerações sobre energia" e por ter colaborado com as "bases empíricas para os princípios fundamentais da ciência, que devem ser reconhecidos como altamente valiosos mesmo por aqueles que pensam que ele foi longe demais em sua depreciação das concepções moleculares." 98

Curiosamente, em seu discurso de premiação em 1909, Ostwald destacou a importância do Energeticismo e de sua abordagem antimecanicista para os seus êxitos no campo da catálise:

"Foi apenas um pouco mais tarde quando eu pessoalmente me virei para o Energeticismo e, assim, me libertei de ideias hipotéticas das quais nenhuma conclusão direta e experimentalmente verificável pode ser obtida, que eu também senti a necessidade de pôr um fim à estagnação em que o estudo dos fenômenos catalíticos acabou como resultado de tais ideias. Lembrei-me dos desenhos ingênuos que um pesquisador conhecido publicara na época para "visualizar" o efeito catalítico do vidro triturado na combinação dos constituintes do gás detonador com aquecimento moderado; os desenhos mostravam como as arestas agudas das lascas de vidro cortavam as moléculas de gás em átomos que eram capazes de se combinar livremente. (...) Assim, aproveitei a oportunidade oferecida em muitos textos, etc. para combater essas hipóteses prejudiciais e chamar a atenção para a incomparavelmente maior eficácia da simples definição de catálise baseada em fatos mensuráveis que afirmam que a catálise é uma aceleração química provocada pela presença de substâncias que não aparecem no produto da reação." ${ }^{\text {"77 }}$

Apesar de finalmente aceitar o atomismo, Ostwald manteve sua crença na energia como base ontológica da realidade e continuou a rejeitar hipóteses sem fundamento empírico. O surgimento da Física Moderna no início do século XX, fez Ostwald acreditar que ideias como o conceito de quantum e a equivalência entre massa e energia proposta por Einstein representassem uma espécie de fusão entre o energeticismo e o atomismo. Contudo, já afastado da ciência há muitos anos, Ostwald não defendeu a retomada do programa científico energeticista, apresentando suas ideias sobre a Física Moderna em alguns poucos escritos, a exemplo de sua autobiografia. ${ }^{18}$

\section{CONSIDERAÇÕES FINAIS}

Ostwald foi durante muito tempo sequestrado de sua própria história. Suas contribuições para a Química foram durante muito tempo minimizadas pela sua rejeição à teoria atômica e aderência ao programa científico-filosófico energeticista. Ao mesmo tempo, quando suas pesquisas científicas são o foco das narrativas, alguns autores tendem a apresentar afirmações gerais sobre seus trabalhos, que normalmente não são apresentados de forma detalhada na literatura.

Neste artigo apresentamos alguns elementos que acreditamos colaborar para uma melhor compreensão da importância de Ostwald para a ciência. Primeiramente, mostramos como sua formação inicial pavimentou o caminho que trilhou na Química. Longe dos grandes centros, Ostwald conheceu teorias e abordagens que estavam fora da agenda dos principais químicos de sua época e reconheceu o terreno fértil da Físico-Química, que começava a se constituir como um campo autônomo. Ele próprio contribuiu para a consolidação dessa disciplina, aproximando-se daqueles que compartilhavam consigo os mesmos interesses de pesquisa e ajudando na divulgação desses trabalhos. Ao mesmo tempo, suas pesquisas sobre afinidades químicas e, posteriormente, da diluição dos ácidos contribuíram para o desenvolvimento de pesquisas sobre o comportamento físicoquímico das soluções. 
Assim como os anos em Tartu contribuíram para seu interesse pela Físico-Química, eles também mostraram a Ostwald a importância de se ensinar, divulgar e organizar o conhecimento químico. Por meio dos seus livros, revistas e, principalmente, do seu papel como professor e orientador, Ostwald colaborou com a rápida formação de uma comunidade de físico-químicos que se estendeu pela Europa e chegou a países como Estados Unidos e Japão.

Entretanto, Ostwald não foi bem-sucedido em todos os empreendimentos nos quais se envolveu. Apesar dos avanços conceituais, Ostwald não conseguiu elaborar uma teoria energeticista que explicasse os fenômenos catalíticos. Do mesmo modo, sua tentativa em sintetizar a amônia não foi exitosa, e o método Ostwald-Brauer para produção de ácido nítrico, além dos obstáculos enfrentados na implementação de uma planta industrial, mostrou-se caro, pouco rentável e não atingiu seu objetivo principal - tornar a Alemanha independente da importação de nitratos, sujeita à interferência de outros países como a Inglaterra. ${ }^{99}$

Por fim, tentamos mostrar a reputação de Ostwald e de suas ações entre seus pares por meio do Prêmio Nobel de Química. As cartas de nomeação mostram a complexidade do legado de Ostwald, que foi indicado pelas mais variadas razões, que vão desde suas pesquisas sobre afinidade química e catálise, até sua filosofia energeticista e suas ações para o ensino, popularização e organização do conhecimento químico - atividades fundamentais para o desenvolvimento da ciência que normalmente são pouco valorizadas pelos cientistas.

Concluímos afirmando que os episódios retratados aqui são um pequeno esboço da extensa biografia de Wilhelm Ostwald - biografia esta que necessita ser revisitada. Poucos personagens na História das Ciências são tão ricos e controversos quanto Ostwald, o que o torna uma figura fundamental para nos ajudar a compreender o passado da química entre os séculos XIX e XX.

\section{AGRADECIMENTOS}

À Royal Swedish Academy of Sciences e Karl Grandin do Nobel Archive pelo acesso às cartas de nomeação apresentadas nesse artigo; Ao CNPq e à CAPES pela concessão de bolsa de pesquisa no exterior; ao CNPq e à History of Science Society pelo financiamento de parte desta pesquisa; à University of Rostock pelo apoio e incentivo durante a realização da pesquisa na Alemanha.

\section{REFERÊNCIAS E NOTAS}

1. Hiebert; E. N.; Körber, H-G. Em Dictionary of Scientific Biography; Gillispie, C. C., Holmes, F. L., eds.; Scribner: New York, 1981, Vol. 15, Supplement I, pp. 455-461.

2. Ertl, G.; Angew. Chem. 2009, 48, 6600 .

3. Bensaude-Vincent; B.; Stengers, I.; História da Química, Instituto Piaget: Lisboa, 1992.

4. Greenberg, A.; Uma breve história da química: da alquimia às ciências moleculares modernas, Blucher: São Paulo, 2010.

5. Maar, J. H.; História da Química. Segunda Parte: de Lavoisier ao sistema periódico, Papa-Livro: Florianópolis, 2011.

6. Rogado, J.; Ciencia \& Educação 2004, 10, 63.

7. Lourenço, I. M. B.; Marcondes, M. E. R.; Quim. Nova Esc. 2003, 18, 22.

8. Souza, F. M.; Aricó, E. M.; Educ. Quím. 2017, 48, 211.

9. Deltete, R. J.; Found. Chem. 2007, 9, 3.

10. Neuber, M. Em Wilhelm Ostwald at the crossroads between chemistry, philosophy and media culture; Görs, B., Psarros, N., Ziche, P., eds.; Leipziger Universitätsverlag: Leipzig, 2005, cap. 4.

11. Pereira, L. S.; Silva, J. L. P. B.; Quim. Nova Esc. 2017, 40, 19.

12. Ostwald, W.; Z. Phys. Chem. 1895, 18, 305.

13. Deltete, R.; Synthese 1999, 119, 45.
14. O trecho citado foi extraído da tradução em língua inglesa da obra: Ostwald, W.; Outilines of General Chemistry, Macmillan and Company: Londres, 1912, p. vi.

15. Oki, M. C. M.; Quim. Nova 2009, 32, 1072.

16. Chagas, A. P.; História da ciência e ensino: construindo interfaces 2011 , 3,7 .

17. Moreno González, A.; Enseñanza de las ciencias 2006, 24, 411.

18. Wilhelm Ostwald, The Autobiography; Jack, R. S., Scholz, F., eds.; Springer International Publishing: Cham, 2017.

19. Butterfield, H.; The Whig Interpretation of History, W. W. Norton \& Company: New York, 1931.

20. Moore, W. J.; Físico-química, Blucher: São Paulo, 1976, Vol. 1.

21. Califano, S.; Storia della chimica: Dalla chimica fisica alle molecole della vita, Bollati Boringhieri: Torino, 2011, Vol. 2.

22. Broda, E.; Ludwig Boltzmann: Man, Physicist, Philosopher, Ox Bow: New York, 1983.

23. Guillén, J. S.; L. E. Boltzmann: el científico que se adelantó a su tiempo, el hombre que lo vivió intensamente, Prensas Universitarias de Zaragoza: Zaragoza, 2009.

24. Kim, M. G.; Affinity, That Elusive Dream: a Genealogy of the Chemical Revolution, MIT Press: Cambridge, 2003.

25. Mocellin, R. C.; Quím. Nova 2006, 29, 388.

26. Müller, I.; A History of Thermodynamics: The Doctrine of Energy and Entropy, Springer-Verlag GmbH: Berlin, Heidelberg, 2007.

27. Nye, M. J.; Before big science: the pursuit of modern chemistry and physics, 1800 - 1940, Harvard University Press: Cambridge, 1999.

28. Servos, J. W.; Physical Chemistry from Ostwald to Pauling: the Making of a Science in America, Princeton University Press: Princeton, 1990.

29. Past, V. Em Estonian Studies in the History and Philosophy of Science; Vihalemm, R., ed.; Springer: Dordrecht, 2001, cap. 3.

30. Ostwald, W.; Volumchemische Studien über Affinität. H. Laakmann: Dorpat, 1877.

31. Ostwald, W.; Volumchemische und optisch-chemische Studien über Affinität. H. Laakmann: Dorpat, 1878.

32. Stock, J. T.; J. Chem. Educ. 1997, 74, 865.

33. Arrhenius, S.; Recherches sur la conductibilité galvanique des électrolytes, P.A. Norstedt \& Söner: Stockholm,1884.

34. Coffey, P.; Cathedrals of Science: The Personalities and Rivalries That Made Modern Chemistry, Oxford University Press: London, 2008.

35. Jack, R. S., Scholz, F., eds.; op. cit., pp. 133-134.

36. Van't Hoff, J. H.; Études de dynamique chimique, Frederik Muller: Amsterdam, 1884.

37. Van't Hoff, J. H.; Z. Phys. Chem. 1887, 1, 481.

38. Arrhenius, S.; Z. Phys. Chem. 1887, 1, 631.

39. Wolfenden, J. H.; Ambix 1972, 19, 175.

40. Ihde, A. J.; The development of modern chemistry, Dover: New York, 1984.

41. Hiebert, E. N. Em Science, Technology \& Society in the Time of Alfred Nobel; Bernhard, C. G.; Crawford, E., Sörbom, P., eds.; Pergamon Press: Oxford, 1982, p. 97.

42. Ostwald, W.; Z. Phys. Chem. 1888, 2, 36.

43. Ostwald, W.; Z. Phys. Chem. 1888, 2, 561.

44. Laidler, K. J.; The World of Physical Chemistry, Oxford University Press: Oxford, 1993.

45. https://www.britannica.com/biography/Wilhelm-Ostwald, acessada em Setembro 2020

46. Jack, R. S., Scholz, F., eds.; op. cit., p. 80.

47. Jack, R. S., Scholz, F., eds.; op. cit., p. 108.

48. Ostwald, W.; Lehrbuch der allgemeinen Chemie, bd. 1: Stöchiometrie, Verlag von W. Engelmann: Leipzig, 1885. No prefácio do Lehrbuch, Ostwald cita alguns trabalhos que foram fundamentais para a escrita do seu livro, dentre os quais o Das optischerehungsvermögen (1878), do químico suíço Hans Landolt (1831-1910); o Die Lehre von der Elektricität 
(1881-1883), do físico Gustav Wiedermann (1826-1899), e a $5^{a}$ edição do Die Moderne Theorien der Chemie (1884, $1^{\mathrm{a}}$ edição 1864), importante obra do químico alemão Lothar Meyer (1830-1895). Ver p. viii.

49. Ostwald, W.; Lehrbuch der allgemeinen Chemie, bd. 2: Verwandtschaftslehre. Verlag von W. Engelmann: Leipzig, 1887.

50. Pereira, L. S.; Tese de Doutorado, Universidade Federal da Bahia, Brasil, 2019.

51. Ostwald, W.; Grundriss der allgemeinen Chemie, Verlag von Wilhelm Engelmann: Leipzig, 1889.

52. Ostwald, W.; Elektrochemie: Ihre Geschichte und Lehre, Veit \& Comp.: Leipzig, 1896.

53. Hapke, T.; Proceedings of the Conference of the History and Heritage of Science Information Systems, Pittsburgh, United States, 1998.

54. Jack, R. S., Scholz, F., eds.; op. cit., p. 177.

55. Pereira, L. S.; Freire Jr., O.; Anais do XVI Encontro Nacional de Ensino de Química e X Encontro de Educação Química da Bahia, Salvador, Brasil, 2012.

56. Ostwald, W.; Die Schule der Chemie, Friedrich Vieweg \& Sohn: Braunschweig, 1903-1904.

57. Hansel, K. Em Mitteilungen der Wilhelm-Ostwald-Gesellschaft; Hansel, K., ed.; Wilhelm-Ostwald-Gesellschaft: Grossbothen, 2004, p. 64.

58. Shuttleworth, S.; Charnley, B.; Notes and Records: The Royal Society Journal of the History of Science 2016, 70, 297.

59. Hapke, T.; Die Zeitschrift für Physikalische Chemie: Hundert Jahre Wechselwirkung zwischen Fachwissenschaft, Komunikationsmedium und Gesselschaft. Verlag Tragott Bautz: Herzberg, 1990.

60. Ostwald, W. Z. Phys. Chem. 1887, 1, 1, p. 3.

61. Ostwald, W. Z. Phys. Chem. 1887, 1, 1, p. 4

62. Schmithals, F. Em Mitteilungen der Wilhelm-Ostwald-Gesellschaft; Hansel, K., ed.; Wilhelm-Ostwald-Gesellschaft: Grossbothen, 2000, p. 51.

63. Filgueiras, C. A. L.; Quim. Nova 2016, 39, 1262.

64. The collected papers of Albert Einstein: The early years, 1879-1902; Havas, P., ed.; Princeton University Press: Princeton, 1987, p. 159.

65. Álvaro Soares Brandão para Wilhelm Ostwald, 18 de abril de 1928, Archiv der Berlin-Brandenburgischen Akademie, NL Ostwald, signature 339, n. $753 / 1$

66. Jones, H. C.; Science 1904, 491, 821, p. 822.

67. Titow, A.; Z. Phys. Chem. 1903, 45, 461, p. 683.

68. Jaffé, G.; J. Chem. Educ. 1952, 29, 230, p. 232.

69. Pereira, L.; Dissertação de Mestrado, Universidade Federal da Bahia, Brasil, 2016.

70. Ostwald, W.; Berichte über die Verhandlungen der KöniglichSächsischen Gesellschaft der Wissenschaften zu Leipzig, MathematischPhysische Klasse 1890, 42, 189.

71. Deltete, R. J. Em The Oxford guide to the History of Physics and Astronomy; Heilbron, J., ed.; Oxford University Press: Oxford, 2005, p. 105.

72. Leegwater, A.; Centaurus 1986, 29, 314.

73. Ostwald, 1892 apud Deltete, R. J.; Found. Chem. 2007, 9, 265 (p. 297). A segunda lei da Energética recebeu várias formulações por Ostwald ao longo de sua obra, de modo que apresentamos apenas uma de suas versões. Sobre o fator de intensidade e a formulação matemática desta lei, ver também ref. 9 e ref. 72 .

74. Ostwald faz alusão ao Pentecostes ao relatar sua conversão ao Energeticismo. Jack, R. S., Scholz, F., eds.; op. cit., pp. 231-233.

75. Kragh, H. Em The Fin-de-Siècle World; Saler, M., ed.; Routledge: New York, 2014, cap. 23

76. Kragh, H.; Quantum generations: A history of physics in the twentieth century, Princeton University Press: Princeton, 2002.

77. Stohmann, F.; 1894 apud Ostwald, W.; Z. Phys. Chem., 1894, 15, 705 (p. 705).

78. Ostwald, W.; Z. Phys. Chem. 1894, 15, 705.

79. Ostwald, W.; Z. Elektrochem. 1901, 7, 995.
80. Apesar da importância de Haber e Bosch no desenvolvimento da síntese industrial da amônia, eles foram reconhecidos em momentos distintos pela Academia de Ciências da Suécia. Enquanto Haber recebeu o Prêmio Nobel de Química em 1918 nominalmente pela síntese da amônia, Bosch recebeu o prêmio em 1931 em reconhecimento à invenção e desenvolvimento de métodos químicos em altas pressões. Ver Laylin, K. J.; Nobel Laureates in Chemistry 1901-1992, Wiley: Washington, 1995.

81. Smil, V.; Enriching the earth: Fritz Haber, Carl Bosch, and the transformation of world food production, MIT press: Cambridge, 2001.

82. Para uma apresentação detalhada sobre as origens e desenvolvimento do método Haber-Bosch, ver Lenoir, T.; Instituindo a ciência. A produção cultural das disciplinas científicas, Unisinos: São Leopoldo, 2003, pp. 256-298.

83. Domschke, J-P.; Hansel, K.; Wilhelm Ostwald: Eine Kurzbiographie, Wilhelm-Ostwald-Gesellschaft: Großbothen, 2000.

84. Zott, R.; Fritz Haber in seiner Korrespondenz mit Wilhelm Ostwald sowie in Briefen an Svante Arrhenius, ERS Verlag: Berlin, 1997.

85. Abelshauser, W.; von Hippel, W.; Johnson, J. A.; Stokes, R. G.; German Industry and Global Enterprise BASF: The History of A Company, Cambridge University Press: Cambridge, 2004.

86. Crawford, E.; The Beginnings of the Nobel Institution: The Science Prizes, 1901-1915, Cambridge University Press: Cambridge, 1984.

87. https://www.nobelprize.org/prizes/chemistry/1909/ostwald/lecture/ acessada em Setembro 2020.

88. Zott, R.; Angew. Chem. 2003, 42, 3990.

89. Bancroft, W. D.; J. Chem. Educ. 1933, 10, 609.

90. Friedman, R. M.; The Politics of Excellence: Behind the Nobel Prize in Science, Times Books: New York, 2001.

91. Apesar de formado em Química e ser reconhecido como físico-químico, Arrhenius manteve uma estreita relação com a pesquisa em Física, realizando pesquisas sobre o Efeito Estufa e Astrofísica, e interagindo tanto com a comunidade sueca de químicos quanto de físicos. O nome de Arrhenius também foi considerado para ganhar o Nobel de Física em 1902 e 1903, mas sua candidatura enfrentou a resistência de alguns membros deste comitê. Por fim, ele acabou recebendo o Prêmio Nobel dedicado à Química, em 1903. Para um melhor entendimento da relação entre Arrhenius e o comitê de premiação em Física, ver Crawford, E.; The Beginnings of the Nobel Institution: The Science Prizes, 1901-1915, Cambridge University Press: Cambridge, 1984, pp. 109-149.

92. Thornstein Hiortdahl, Johann H. L. Vogt, Waldemar C. Brögger and Heinrich Goldschmidt to Nobel Committee of Chemistry, 23 January 1907, the Nobel Archives, The Royal Swedish Academy of Sciences, Stockholm.

93. Emil Constam to Nobel Committee of Chemistry, 15 February 1908, the Nobel Archives, The Royal Swedish Academy of Sciences, Stockholm.

94. Theodore Richards to Nobel Committee of Chemistry, 04 January 1905, the Nobel Archives, The Royal Swedish Academy of Sciences, Stockholm.

95. Em 1905, Ostwald atuou como professor visitante na Universidade de Harvard, Dentre as disciplinas ministradas por ele nesta instituição, encontra-se uma disciplina sobre Filosofia Natural. Tal fato mostra o quanto Ostwald estava envolvido com questões filosóficas na época de sua nomeação por Richards (ver ref. 18 e ref. 28). Do mesmo modo, o programa científico energeticista também figurava dentre os interesses, ver Ostwald, W.; J. Chem. Soc., Trans. 1904, 85, 506.

96. Paul Walden to Nobel Committee of Chemistry, 09 January 1904, the Nobel Archives, The Royal Swedish Academy of Sciences, Stockholm.

97. Crawford, E.; Isis 1984, 75, 503.

98. Arthur A. Noyes to Nobel Committee of Chemistry, 16 January 1906, the Nobel Archives, The Royal Swedish Academy of Sciences, Stockholm.

99. Stevenson, D.; 1914-1918: a história da Primeira Guerra Mundial, Novo Século: Barueri, 2016. 